\section{Edycaçäa

\section{Editor}

Maria Inês Côrte Vitoria PUCRS, RS, Brasil

\section{Equipe Editorial}

Pricila Kohls dos Santos PUCRS, RS, Brasil

Marcelo Oliveira da Silva PUCRS, RS, Brasil

Carla Spagnolo

PUCRS, RS, Brasil

Rosa Maria Rigo

PUCRS, RS, Brasil

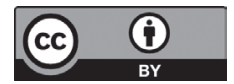

A matéria publicada neste periódico é licenciada sob forma de uma Licença Creative Commons - Atribuição 4.0 Internacional. http://creativecommons.org/licenses/by/4.0/

\title{
Conhecimento como invenção: Paul Valéry no ensino da educação contemporânea
}

\author{
Knowledge as invention: Paul Valéry in contemporary education teaching
}

\author{
Máximo Daniel Lamela Adóa \\ Maria Idalina Krause de Campos ${ }^{b}$ \\ Sandra Mara Corazzac
}

RESUMO: O artigo Conhecimento como invenção: Paul Valéry no ensino da educação contemporânea analisa as possibilidades de um fazer potente em Educação, tendo como foco principal uma criatura de pensamento - o poeta, filósofo e crítico da cultura Paul Valéry. Propõe atuar e operar com um método do informe para o Ensino de uma Educação Contemporânea por meio da utilização da noção de Conhecimento como Invenção, em que o espírito busca inventar um possível e permissivo operar de uma consciência de si com relação aos movimentos do intelecto que seja ampla, ou seja, com a procura do uso mais pleno de suas faculdades intelectivas. Desse modo, o artigo vale-se do pensar valéryano para o desenvolvimento de uma maneira de lidar com o Ensino de uma Educação Contemporânea com vistas a uma Educação espiritual potente, oriunda, também, de uma self-variance disciplinada. A variação espiritual no Ensino de uma Educação Contemporânea atua e opera a partir da perspectiva valéryana em cruzamentos imaginativos com a filosofia, a literatura e as ciências humanas e sociais. Trata o conhecimento como invenção de uma produção singular que cultua o intelecto na busca do Eu puro - senhor de si - e transita aventureiramente por diversas áreas do saber.

Palavras-chave: Valéry. Conhecimento. Invenção. Ensino. Educação.

ABSTRACT: The paper Knowledge as invention: Paul Valéry in contemporary education teaching analyzes the possibilities of a potent action in Education by focusing on a thought creature - the poet, philosopher and culture critic Paul Valéry. It proposes to act and operate with the method of inform in Contemporary Education Teaching by using the notion of Knowledge as Invention, according to which the spirit attempts to design a possible and permissive operation of broad self-consciousness in relation to intellect movements, i.e. by attempting to use

a Pós-doutorando da UFRGS com Bolsa PDJ do CNPq. Doutor em Educação - UFRGS. <maximo.lamela@ufrgs.br>.

b Doutoranda em Educação - UFRGS com Bolsa CAPES/INEP - Membro do Observatório da Educação CAPES/INEP - Núcleo UFRGS. <idalinakrause@yahoo.com.br>.

c Professora Titular da Universidade Federal do Rio Grande do Sul, Faculdade de Educação, Departamento de Ensino e Currículo, Programa de Pós-Graduação em Educação, Linha de Pesquisa Filosofias da Diferença e Educação. No Diretório dos Grupos de Pesquisa, líder do grupo "DIF - Artistagens, Fabulações, Variações". Pesquisadora de Produtividade do CNPq, nível 1D. Coordenadora Geral do Projeto Escrileituras: um modo de ler-escrever em meio à vida, integrante do Programa Observatório da Educação, CAPES-INEP. < sandracorazza@terra.com.br>. 
intellective faculties more broadly. Hence, this paper has employed the Valéryan thought for the development of a way of dealing with Contemporary Education Teaching aiming at a powerful spiritual Education also derived from disciplined self-variance. Spiritual variation in Contemporary Education Teaching acts and operates from the Valéryan perspective through imaginative intertwining with philosophy, literature and human and social sciences. It addresses knowledge as invention of a singular production that both cultivates the intellect in search of the pure - self-possessed - Self and adventurously moves through a number of knowledge areas.

Keywords: Valéry. Knowledge. Invention. Teaching. Education.

$\mathrm{O}$ pensamento não pode prescrever a si mesmo, nos diz Paul Valéry (1947). Dar ao próprio pensamento uma definição mais ou menos clara ou definitiva seria como dar a ver uma impossibilidade. Ou seja, mesmo que pudéssemos observar uma gravação de nossos próprios pensamentos não estaríamos observando, de fato, o pensamento e tampouco o seu movimento, pois, inclusive essa ordem, mesmo que expressa - a do movimento do pensar, ou, do mesmo modo, o seu processo - não seria ele, e sim algo como um penso pensar o pensamento pensado. O objeto limpo único e perpétuo do pensamento seria o que não existe de modo finito, algo como um finito passado. Aquilo que já não está, numa perpétua tentativa, diante mim. O impossível, assim como o exercício de tentar pular a própria sombra.

Nesse sentido, Paul Valéry toma o pensamento como um modo privilegiado de dar especial atenção às invenções do intelecto - a partir de um Eu-função, pode-se desenvolver uma consciência do processo do pensar para fins de conhecimento.

Pensar está na ordem da ficcionalização e construção de realidades que são, cada uma ao seu modo, sempre inventadas, assim como aquilo que se sabe de si, do mundo e suas relações. No âmbito da Educação Contemporânea, especialmente no que tange à prática de ensino, esse pensamento ganha e doa força na medida em que se toma esse Eu-função como um modo de operar a singularização e não individualização. O que se conforma pelo processo de um Eu-função, como veremos adiante, é uma singularidade e não uma identidade. Quando há uma identidade possível na relação entre indivíduos ela, jamais, pode ser prevista antes da relação e tampouco pode ser estabilizada imediatamente depois. Não há identidade fora de qualquer relação, deste modo o que importa não é a identificação - exercício homogeneizador de diferenças por meio da distinção de iguais -, mas, justamente, a potência da singularização na atuação das relações entre indivíduos.

Paul Valéry em toda sua trajetória de vida pesquisou, estudou, escreveu sobre conteúdos das mais diversas áreas do conhecimento. Misto de poeta, pensador e crítico da cultura possui uma forma original de lidar com o espírito, tendo sido traduzido por escritores e também poetas em vários idiomas: Augusto de Campos (para o português); Jorge 
Guillén (para o espanhol); Rilke (para o alemão). No entanto, apesar de possuir um reconhecimento internacional pelo conjunto de suas obras produzidas é ainda pouco explorado no Brasil. Principalmente no que tange ao uso - teórico prático - de seu pensamento no campo da Educação. Daí a importância de um debruçar-se mais efetivo sobre seu pensamento, assim como sua vida e seus escritos de formas variantes (diálogo, prosa, poesia, ensaio, carta, discurso, aula) e que contemplam uma multiplicidade de áreas do conhecimento como: filosofia, matemática, música, poesia, teatro, além de análises e críticas sobre cultura e sociedade.

Paul Valéry possui um pensamento vivo! Pode ser lido como um educador por sua dinâmica textual sempre em transição, visto que consideramos que a formação espiritual de um educador se encontra em constante estado de devir e mutação. Trata-se de um leitor ávido, um escritor compulsivo, um observador da arte e da vida como obra de arte. Um pensador que busca, no movimento de leitura e escrita, exercitar conscientemente os pensamentos. Verificando no que estes implicam, procura vê-los com precisão e pesquisar seus labirintos, sua mecânica psíquica íntima, seu método operativo.

Desse modo Paul Valéry compõe uma escrita nada convencional e bastante digressiva. A produção valéryana está longe de ser um sistema filosófico, nela não se verifica uma cronologia ou sistematização de regras fixas. Não há hierarquia de escrita, mas graus de importância de acordo com a temática desenvolvida a cada momento. Tal temática e seu desenvolvimento pode no instante seguinte de sua produção ser deixada de lado, como um rascunho, uma anotação, um desenho, podendo voltar a circular à medida que se funda ou se mescle, com uma nova temática em foco. Aborrece-lhe a ideia que vem de primeira, tem gosto por fazer um trabalho de composição; que proporciona ao espírito transformações meditadas, um esforço intelectual, um esmero da criação e do querer fazer. Onde o escritor, e consequentemente o pensador, define-se, segundo ele: "através da relação entre um certo 'espírito' e a linguagem [...]" (VALÉRY, 2011, p. 179).

Este texto trata de abordar o tema da construção do conhecimento via um modo de lidar com o pensamento e seu legado para a Educação. Tal modo procura ter a invenção como um procedimento que coloca o pensamento sempre em movimento e para que isto ocorra o mesmo não pode estar dissociado da vida, ou seja, de seu próprio movimento na cotidianidade ordinária. O texto apresenta o tema por meio de quatro tópicos: 1) Self-variance [autovariação] - observa um modo valéryano de conceber o Eu empírico como uma função para alcançar o Eu puro, ou seja, o pensamento; 2) Conhecimento e linguagem - apresenta como Paul Valéry lida com o cartesianismo e o transforma em uma força inventiva que se vale da linguagem para construir conhecimento a partir de si; 3) Método do Informe - expõe experimentos de um modo de desenvolver pesquisa no ensino de uma Educação contemporânea; 4) Como fazer? - afirma que o trabalho da docência é um trabalho de pesquisa e mostra alguns caminhos percorridos no exercício empírico da apropriação desse pensar para a Educação e, especialmente, para o ensino. 
O texto se desloca por esses tópicos e, com eles, deseja abrir caminho para o debate a respeito da pesquisa e de modos de conceber o ensino na Educação Contemporânea.

\section{Self-variance [autovariação]}

Paul Valéry utiliza-se da palavra francesa esprit para aludir ao Eu. Mas há em seu pensamento a distinção entre dois tipos de espírito: Moi que seria o Eu empírico (self-variance) e Moi que seria o Eu puro (Idolle de l'Intelect) a ser cultuado, buscado. Este conceito de Eu puro deve ser entendido com uma significação particular: o Eu como consciência de si, intelecto, inteligência. Um Eu que atua como um sujeito que não se assujeita, mas aspira e realiza a criação, sem divindade reguladora, sem idealismo (Eu absoluto do Idealismo Alemão) e distante da metafísica da alma imortal (Eu substancial do racionalismo de Descartes). Portanto o Eu puro valéryano não guarda uma moralidade, consistindo na invariabilidade, naquilo que não muda no espírito. $\mathrm{O}$ espírito como um signo de pura possibilidade, de uma virtualidade. Um estado de espírito ao qual o Eu empírico aspira e tende. Eu que passa por uma ascese e encontra-se - purificado de paixões, de outros ídolos e idolatrias - liberto para agir e pensar.

Para Valéry espírito é também uma palavra infinita que evoca a origem e o valor de todas as demais palavras. Espírito é possibilidade, necessidade, energia, capacidade de transformação, aventura intelectual que tem na linguagem um meio para expressar ideias. É tarefa do espírito, aumentar os graus de sua racionalidade, via consciência e atenção na atividade intelectual.

Valéry, na primeira fase de suas obras, busca o espírito que se pensa a si mesmo, um espírito puro sem corpo e sem matéria. Numa segunda fase, já na década de vinte do século passado, ocorre uma ligação entre os processos psíquicos e as atividades fisiológicas corpóreas, em que o espírito faz uma mediação entre os processos do corpo e os mentais.

Espírito e verbo são quase sinônimos para Valéry. Verbo vem do grego lógos que simultaneamente quer dizer: cálculo, palavra, discurso, conhecimento, ao mesmo tempo também designa expressão. Assim o verbo que é primeiro coincide com o espírito que também o é. O espírito é, pois, potência de vida. Aberta para a aventura extraordinária da existência!

Valéry é um apaixonado pelas luzes do Iluminismo e do sensualismo-materialista do Século XVIII - o que pode soar contraditório -, o que lhe interessa na verdade nessas correntes, são as arquiteturas da forma do texto, seus métodos de composição, suas forças compositivas, nos quais o meio de ocorrência textual é mais importante do que um fim ou meta. Em seu texto $A$ Tentação de (São) Flaubert, Valéry fala sobre uma diabólica tentação, humana 
e poética para provocar uma escrita amebiana, um meio para um jogo de uma escrita do vivível: “[...] viver é, a todo instante, sentir falta de alguma coisa - modificar-se para atingi-la - e, desse modo, tender a substituir-se no estado de sentir falta de alguma coisa" (VALÉRY, 2011, p. 83). Trata-se de um movimento corpóreo como o feito pela ameba, ou seja: de transubstanciação com o objeto amado. Pois "[...] vivemos do instável, pelo instável, no instável: essa é a função completa da Sensibilidade, que é a mola diabólica da vida dos seres organizados" (VALÉRY, 2011).

Valéry tem um olhar comparado ao o de uma serpente: obsessivo, metódico, disciplinado, que pesquisa as operações espirituais de como se dá o pensamento, percorrendo trajetórias, refazendo caminhos potenciais ainda não descobertos. Uma Ofis-sofia (CAMPOS, 1984, p. 69), composição de operações intelectivas constantes, como de um educador espiritual sem trégua, a buscar meios para poder sê-lo.

Segundo Valéry “[...] não pode haver um modo novo de ver sem um modo novo de pensar” (2011, p. 33). Estas operações - novo-ver, novo-pensar - desenham mapas mentais, guias, para um enfrentamento ao pensamento do senso-comum compreendido como paralisante e impotente. Abrindo vãos para uma retina imanente que espia; a intensidade deste olhar é educativa, proporciona um novo desenvolvimento potencial, através de forças capturadas e tem nelas, combustível, para novos fazeres espirituais. São tramas - como alude Valéry - que se apresentam ao espírito, uma diversidade em meio à qual não há uma determinação única e ilusória que imita o real, mas o possívela-cada-instante de um texto que se compõe. Escrita, alinhavada entre fluxos de correntes energéticas, onde pulsa o espírito e a mão escreve esboços "[...] da individualidade de uma jornada, de uma estação, de uma vida" (DELEUZE, 1994, p. 57- 65). Para Valéry, assim como para Spinoza, o espírito é inseparável da matéria e a matéria é inseparável do espírito (ADÓ, 2012). O espírito é sempre visto em circunstância, em situação, num dado tempo e espaço, em sua fragilidade real. Segundo Pimentel diante do vivível o espírito encontra-se, "condicionado a si mesmo, aos outros e ao mundo" (PIMENTEL, 2008, p. 33) e não evoca um eu substancial, mas um eu funcional, ou seja, um eu sempre em relação.

Paul Valéry trata o espírito como o Eu funcional inseparável da matéria, dotado de uma consciência e inteligência mutável que utiliza seu trânsito pela existência e pensa-se. Diferentemente de René Descartes, que afirma: Penso, logo existo, Valéry tem como foco: O que é que em nós está pensando, quando se pensa (VALÉRY, 1996). Um Eu como função do próprio pensamento e não como essência "Ego", mas como atividade funcional para pensar. Um espírito operador que compõe uma comédia do intelecto à medida que se mostra a si mesmo à luz do dia. Um Eu operador consciente, Eu puro como Leonardo Da Vinci, que "guarda, esse espírito simbólico, a mais vasta coleção de formas, um tesouro sempre claro às atitudes da natureza, um poder sempre iminente e que cresce de acordo com a extensão de seu domínio" (VALÉRY, 1998 p. 55). 


\section{Conhecimento e linguagem}

Conhecer é lidar com a linguagem. Para Paul Valéry em todo o saber científico moderno está incorporada uma vontade de poder. Esta vontade de poder está associada à crença na verdade dos enunciados científicos, uma vez que os mesmos são passíveis de aplicação e verificação empírica. No entanto, observa Valéry, nada disso seria possível fora da linguagem. Cabe chamar a atenção de que essa noção de verificação científica procede de um legado do pensamento cartesiano como a ideia do eu que pensa a si mesmo, ou seja, da fórmula de Descartes: cogito ergo sum [Penso, logo existo] e esta, a sua vez, decorre na separação entre sujeito e objeto, uma vez que separa o sujeito que pensa do objeto pensado ou pensamento.

Paul Valéry chamará esse procedimento de egotismo, ou seja, um modo de atenção a si mesmo. Ao apresentar o livro de Descartes Discurso do Método ele diz: "Servindo-me duma palavra de Stendhal, que a introduziu em nossa língua, e a desviando um pouco para o meu uso, direi que o verdadeiro Método de Descartes devia se denominar o egotismo, o desenvolvimento da consciência para os fins do conhecimento" (1955, p. 57).

É justamente isto que ele chama de egotismo o ponto de contato que Valéry encontra entre seu pensamento e o de Descartes. No entanto, o egotismo valéryano se resguarda no espaço da linguagem e, por isso, na instância inseparável entre sujeito que pensa e objeto pensado. Como observam Brutus Pimentel (2008) e Karl Löwith (2009), uma atenção a si mesmo equivale dizer uma atenção ao Eu ou ao Espírito pelo movimento de um pensamento que se pensa.

Ao falar de Descartes e, principalmente, a respeito do cartesianismo, Valéry afirma:

[...] todo sistema é uma empresa do espírito contra si mesmo. Uma obra exprime não o ser, dum ator, mas sua vontade de parecer, que acolhe, ordena, combina, disfarça, exagera. Quer dizer que uma intenção particular trata e trabalha o conjunto dos acidentes, dos jogos do acaso mental, dos produtos de atenção e de duração consciente, que compõem a atividade real do pensamento; mas esta não quer parecer o que é: quer que essa desordem de incidentes e atos virtuais não entre em linha de conta, que suas contradições, seus equívocos, suas diferenças de lucidez e de sentimentos sejam reabsorvidos. Disso resulta que a reconstituição dum ser pensante, baseada no exame dos textos, conduz à invenção de monstros, tanto mais incapazes de vida quanto mais cuidadosa e rigorosamente elaborado tenha sido o estudo, chegando-se a operar conciliações de opiniões que não são jamais produtos do espírito do autor, a explicar obscuridades por ele suportadas, a interpretar termos cujas ressonâncias eram singularidades desse espírito, a ele próprio impenetráveis. Em suma, o sistema dum Descartes não representa o mesmo Descartes senão como manifestação de sua ambição essencial e de seu modo de a satisfazer. Mas em si, é uma representação do mundo e do conhecimento que não poderia absolutamente deixar de envelhecer, como envelhece uma carta geográfica. (VALÉRY, 1955, p. 21-22)

Educação Por Escrito, Porto Alegre, v. 6, n. 1, p. 81-97, jan.-jun. 2015 
Pode-se perceber que Paul Valéry se apropria do pensamento de Descartes para dizer com ele e contra ele que toda a filosofia cartesiana trata de uma confissão e suposição explícita de seu EU. Considera a obra de Descartes e apreende da mesma a ideia de um pensamento que se pensa e, também, a noção e implicação antifilosófica da filosofia. Trata-se de apreciar em Descartes a potência inventiva de seu método. Antes de conciliar opiniões, partir delas para a constituição de novas singularidades para o pensamento e, consequentemente, para o sujeito que pensa. No sistema cartesiano nada parece haver no conhecimento que não possa ser elucidado, transformado em saber utilizável e sólido com a ressalva de que: "Um método não é uma doutrina: é um sistema de operações que realize melhor que o espírito entregue a si próprio o trabalho do próprio espírito" (VALÉRY, 1955, p. 28).

O que propugna Descartes no Discurso do método é alcançar uma certeza de si mesmo e é nesse ponto, aparentemente de âmbito pessoal e singular que Valéry vê sua potência e universalidade. A atualidade de Descartes está, para Valéry, em ter-se atrevido a começar de novo. A repreender a filosofia que já conhecia e travar um novo empreendimento filosófico a partir de si. Mas, adverte que é isso o que lhe importa em Descartes, a forma de seu pensar e não o conteúdo conciliatório que derivou de seu pensamento, pois o mesmo é datado e temos de tomá-lo com a leitura e as necessidades de nosso tempo. Afirmar: Existo, observa Valéry, não tem sentido, ao menos que a pessoa seja tomada por morta (1955, p. 34). Mas, é justamente essa afirmação que coloca em relevo a fusão que há na produção do conhecimento como um amálgama da linguagem com aquilo que se passa; aquilo que provoca uma emissão particular, uma observação e, também, uma representação ou sensação de sensibilidade análoga. No entanto, ou, em último caso, "[...] a palavra, produzindo-se como consequência imediata, tem a insignificância e o valor de um reflexo" (VALÉRY, 1955, p. 35), ao voltar o pensamento para essas palavras se verifica que elas "[...] nada significam por si mesmas, tendo, porém, desempenhado um papel instantâneo durante uma brusca modificação da expectativa ou da orientação íntima de um sistema vivente" (idem, p. 35-36).

O Cogito, para Valéry, é um ato reflexo do homem, o irromper de um ato. A potência do pensamento como um modo de alcançar o conhecimento está presente nesse ato. Há nele a força de uma política interior em relação com outra que lhe é exterior e ao encontro dessas forças podemos chamar de invenção. Trata-se da tentativa, sempre inconclusa e inesgotável, de colocar em palavras as atitudes comuns de todos os homens dedicados à reflexão. A esse movimento de um pensamento dos espíritos dedicados à criação Valéry denominou comédia do intelecto ou comédia intelectual. Em uma passagem de Tel Quel I mais precisamente em Cahier B conjunto de textos de 1910, Valéry afirma que filosofar só é possível, justamente, pela impossibilidade de registrar as intuições; observá-las em estado puro. E se pergunta: Se quando um pensador fala do ser pudéssemos olhar para o que ele pensa nesse exato momento o que encontraríamos? O que é o Cogito exceto a tradução de um estado intraduzível? E, na sequencia, temos a afirmação: É perfeitamente inútil um saber que não posso modificar (VALÉRY, 1943, p. 188). 
O cogito ergo sum cartesiano funciona, assim posto, como um cenário, ou melhor, um palco bem montado para a dramatização do intelecto. Trata-se de fazer do pensamento um impulso para a criação, sempre inventiva, do conhecimento.

A intenção de Descartes, segundo Valéry, foi a de empreender uma grande aventura intelectual - a sua grande aventura - e fazer com que aqueles que tomassem contato com seus escritos pudessem escutar seu próprio eu, pois: "Jamais, até ele, filósofo algum se havia tão deliberadamente exposto sobre o teatro do seu pensamento, pagando com a sua pessoa, exibindo o seu Eu durante páginas inteiras [...]” (idem, p. 36). É interessante ressaltar as próprias palavras de Descartes na Primeira Parte de Discurso do Método: "Assim, o meu intuito não é ensinar aqui o método que cada um deve seguir para bem conduzir a sua razão, mas apenas fazer ver de que maneira tratei de conduzir a minha" (DESCARTES, 1955, p. 67).

Tomado por esse egotismo cartesiano Valéry escreve, e publica em 1895, Monsieur Teste (1997). Trata-se da vida e os pensamentos de um personagem tido como um discreto burguês e interpretado pela crítica e pelos leitores em geral como a construção de um alter ego de Paul Valéry. No capítulo denominado "Carta de Madame Émile Teste" no conjunto de textos que compõem o livro, podemos ler: "Nunca pensamos que o que pensamos esconde de nós o que somos" (VALÉRY, 1997, p. 37); em outro fragmento do conjunto, intitulado "Trechos do log-book de Monsieur Teste" lemos: "Confesso que fiz de meu espírito um ídolo [...]" (idem, p. 56). O que movimenta Monsieur Teste é toda uma relação com o EU e nisso a criação de um personagem para pensar o pensamento. É "demónio da possibilidade" (idem, p. 11) tomado pelo egotismo cartesiano.

O que lemos no conjunto valéryano não mais fundamenta um sujeito da razão como aquele fundado no "Penso, logo existo" do Discurso do Método de Descartes. Aquilo que em Descartes seria uma íntima revelação de uma presença originária e imediata, surge, em Monsieur Teste, como um espaço de ficção que poderíamos denominar: teatro do espírito.

O mundo moderno, na esteira da filosofia cartesiana, inaugura o mundo da representação com relação ao pensamento. As categorias de sujeito e objeto se constituem como categorias indissociáveis e complementares da representação. A categoria de representação do modelo cartesiano converte-se em uma relação privilegiada para o conhecimento. Desse modo, o pensar atua como sinônimo de representar e obedece a relação da representação com o representado: sujeito e objeto, idea como perceptio.

Verificando uma consistência puramente linguística do Eu, Valéry dissolve com facilidade toda essa ilusão de realidade doada pela obediência da relação de representação com o representado quando transforma esse ser da consciência em uma impossibilidade do próprio pensamento, ou seja, uma invenção funcional para lidar com os modos de conhecer. 
Podemos observar que há na produção valéryana certa rejeição a uma metafísica do sujeito, poderíamos dizer que se trata de um rompimento de uma filosofia essencialista como a filosofia da consciência ao adotar uma filosofia da linguagem. Essa rejeição de uma metafísica do sujeito está, justamente, acompanhada de uma crítica aos valores dualistas da modernidade filosófica.

O pensamento contemporâneo, preocupado com a complexidade das relações em todos os âmbitos, ergue-se, justamente, por meio da rejeição da definição de um sujeito universal, estável, unificado, totalizado e totalizante e, com isso, interiorizado e individualizado. Uma vez que admite que o sujeito moderno do cartesianismo esconda, em seus pressupostos essencialistas, a noção de que sua constituição é fabricada e essa fabricação está permeada de valores e vontades de poder.

A problemática exposta nessa contenda, qual seja: a da constituição de um sujeito, relacionada com a discussão a respeito de um Eu é a mesma que instaura uma crise da representação [a do próprio eu] na e da modernidade filosófica. Tal crise pode ser observada já na constatação de que o ego cogito ergo sum de Descartes se funda em uma representação do Eu que procura instaurar certa estabilidade para o pensamento e, consequentemente, para um eu pensante como subjectum (sujeito).

Em um texto dedicado ao pensamento nietzschiano, Martin Heidegger (2000) explicita que Descartes inaugura a ideia de que toda consciência das coisas, e do ente em sua totalidade, é reconduzida a uma autoconsciência do sujeito humano como fundamento inabalável de toda certeza. Com esse movimento o cogito cartesiano fundamenta a ideia de que a realidade do real é o ser representado por meio do sujeito representante e, ainda, para este mesmo sujeito representante. Temos aí uma circularidade vertiginosa, onde o Eu é uma co-representação de si mesmo. Uma consciência unitária e autoidêntica, ou seja, constitui-se como referência última de si mesmo. Com isso a verdade cartesiana se fundamenta pela certeza de si como sujeito humano; deste modo o homem passa a regular e figurar um papel especial na história da metafísica, pois passa a desenvolver, fundamentar e constituir o conhecimento metafísico sendo, também, quem o transmite e o deforma. O homem cartesiano se constitui como sujeito de toda objetividade e centro dessa relação sujeito-objeto fundamentando a verdade enquanto certeza como uma marca da modernidade. É, segundo Heidegger, nesta fundamentação cartesiana, a do cogito ergo sum, que ocorre o mascaramento da constituição de um Eu estável e plano para a recorrência da verdade como certeza na adequação. É via essa estabilidade de um Eu como a fixação de um real e representação de um sujeito privilegiado que este mesmo Eu passa a ser o ponto onde tudo se mostra e por meio do qual se possa assegurar a realidade como certeza. Nesse sentido, Heidegger afirma que a verdade cartesiana se funda na certeza, isto é, na certeza do cogito no qual o (Penso, logo existo) pode ser lido como um (eu represento, logo existo), pois com essa proposição Descartes inaugura uma nova postura para o humano. O homem não é mais aquele que assume 
uma doutrina como uma condição de fé, mas tampouco adquire o conhecimento do mundo por qualquer via. Ele o representa.

Com o cogito cartesiano o homem passa a crer, com uma certeza incondicional, que é ele o ente cujo ser possui maior certeza e, deste modo, converte-se no fundamento e medida, (autofundante e, portanto, fabulação posta pelo próprio homem), de toda certeza e verdade. Heidegger explicita que o pensamento de Descartes, como marca da metafísica da modernidade, transfere a humanidade e sua história de um âmbito que podemos definir como o de uma especulativa verdade da fé do homem cristão ao de uma representatividade do ente fundado no sujeito. Neste fundamento essencial se torna possível a moderna posição dominante do homem e com ela a ideia de estabilidade e centralidade de uma consciência humana.

Valéry, ao ter de escrever sobre Descartes, se dá conta dessa trama e procura se apropriar do que há de melhor nesse pensamento. Faz o que ele chama de comédia do intelecto. Ao invés de condenar os movimentos realizados pela intelectividade cartesiana - com relação ao seu legado para a cientificidade - se apropria deles e, num movimento simples dotado na potência do pensamento literário, desmonta o essencialismo fundado na verdade de um sujeito ofertando uma verdade instável - como é sua própria fundamentação - por meio da linguagem de um eu como self-variance. E esse eu importa, pois, na acepção valéryana “[...] na verdade, não existe teoria que não seja um fragmento cuidadosamente preparado de alguma autobiografia" (VALÉRY, 1991, p. 204).

Tomar a perspectiva valéryana para o ensino tem como objetivo reforçar a ideia de que a expressão de uma prática educacional que valorize as singularidades - antes que reafirmar identidades homogeneizando culturas via a pasteurização dos procedimentos educacionais, - esteja em seu processo e não em alguma metodologia com fins que se traçam para além dela mesma. A ideia é a de fortalecer a imagem de uma Educação intransitiva, que não se estabelece como mediação, no sentido de explicar o mundo, mas interroga-o de forma indireta ao transformar a explicação em espetáculo auleiro, ou melhor, em estratégia poética, e por isso política. Uma Educação-tarefa que se constitua em si mesma como um fazer e não funcione apenas como suporte ou instrumento de uma atividade que deverá ocorrer ou ocorre de modo paralelo. Nisto o processo passa a atuar como acontecimento e o acontecimento passa a ser o sentido imanente dessa prática.

\section{Método do informe}

O método do informe possibilita o desenvolvimento de um tipo de pesquisa em Educação em que se possa, justamente, enfrentar as dificuldades de pensar o informe (CORAZZA, 2014). Trata-se de uma composição que tem em vista valorizar a pesquisa do espírito humano juntando as proposições sobre o espírito, como explicitadas por 
Paul Valéry, à filosofia da diferença, em especial, aquela desenvolvida por Gilles Deleuze. Tal método se insere no campo das pesquisas pós-críticas na Educação. Trata-se de um modo de fazer pesquisa que tem como perspectiva a interrogação e a variação durante todo o processo. Não possui regras fixas para não matar o prazer do inusitado. Mas se vale de um obstinado rigor [hostinato rigore] (VALÉRY, 1998, p. 13) - procedimento tomado de Valéry que, a sua vez o tomou da divisa de Leonardo da Vinci assim como, de outro modo, dos textos de Edgar Allan Poe -, para dar uma especial atenção às tramas complexas que entram na confusão do intelecto voltado a criar conhecimento.

O método é o de capturas de forças dos textos, das imagens, das musicalidades, das vozes, dos conhecimentos, de tudo que devém em vida potente sendo apropriado para o ensino e suas práticas, pois como alude Valéry “[...] é o que contenho de desconhecido a mim mesmo que me faz ser eu mesmo" (VALÉRY, 1997, p. 59).

Os procedimentos utilizados na pesquisa são operações inventivas de um pensamento que busca investigar problemas, diante das nuances do ensino, tentando, por seus próprios meios, envolve-los em um desenvolvimento que evite a mediocridade e aposte na experimentação de novos meios.

Através dos conhecimentos adquiridos, no próprio processo de pesquisa assim como na história do desenvolvimento teórico-prático do campo, propõe um novo fazer. Digamos que se procura agir como um Robinson Crusoé que na concepção de Valéry, aludindo a Daniel Defoe para falar de seu próprio espírito problemático de poeta e pensador: "[...] numa ilha de espírito e carne, rodeado por todas as partes de ignorância, a fabricar generosamente seus utensílios e sua arte" (PIMENTEL, 2008).

Assim o espírito opera por necessidade, passando a viver num estado de existência compositiva, que pressupõe um fazer expresso via, principalmente, da escrita. Tendo na grafia da palavra regada, no conceito dramatizado, um valor potencial de uma escritura que emerge do punho, da mão que rabisca, expressando os pensamentos de um espírito amante. Enamorado este espírito que nada mais é que um serpensamento arrisca um novo olhar diante da realidade do mundo espetacular: "Uma forma de pensar circuloviciosa, um serpensamento, a que não estão alheios os universos tautológicos de Mallarmé e de Joyce, do lance de dados ao riocorrente, que retorna a si mesmo por um cômodo Vicus de recirculação... PEN(T)SER." (CAMPOS, 1984, p. 23). Um espírito que quer dizer-se, autoeducar-se, explorando as potências da linguagem dentro de um processo de culto ao intelecto. Método que sonha com um Educador à procura de um Eu puro, senhor de si e que se experimenta em uma comédia intelectual antropofágica.

Voltada ao drama das existências espirituais dedicadas a compreender e a criar, vai ao mundo de outras criaturas de pensamento para de suas obras analisar o que sobressai em algum ponto e dele passa a extrair fragmentos, uma fração capturada que o leva a pensar em o nome da criatura estudada como "um signo" (VALÉRY, 1998, p. 9), e assim passa a explorar, inventar e transmutar o vivível, indo além do que já se tem ciência. 
E a partir desta operação de colheita espiritual, vivido em coexistência percorrendo, vidas e obras, dá asas à imaginação e com ela sobrevoa caminhos e trajetórias, becos e vielas, que foram utilizados prodigiosamente como tessitura de ações criadoras de um espírito pensante. Movimentos febris, "de um espírito que deseja imaginar um espírito" (VALÉRY, 1998, p. 11) audaz, refazer esse trajeto de pensamento e conceber assim, uma nova imagem que é dada por nós, - via malha intelectiva, - oriunda dos labirintos e das entranhas da imaginação. Um espírito de escrita serpenteada, um operador que transforma para si tudo o que existe.

O Método do Informe para a pesquisa em Educação procura atuar como Edmond Teste, personagem de Monsieur Teste de Valéry, que opera com o que lhe é proposto "[...] manipulando e mesclando, fazendo variar [...] podendo cortar e desviar, esclarecer, congelar isto, aquecer aquilo, afogar, realizar, nomear o que não tem nome, esquecer o que queria, adormecer ou colorir isso ou aquilo" (VALÉRY, 1997). Desse modo o espírito compõe um novo mundo e nele passa a habitar. Procura criar possibilidades para um serpensamento, uma forma de pensar que por vezes se torna protagonista voraz e satânica e que serpenteia nos labirintos do espírito mordendo o que pode.

Nesta trajetória é preciso se ater aos detalhes. Como Marcel Schwob em Vidas imaginárias, é preciso procurar estar do lado da arte que "[...] está no oposto das ideias gerais, só descreve o individual, só deseja o único. Ela não classifica; desclassifica" (SCHWOB, 1997). Procura-se um modo de lidar com o ensino que se possa operar a arte da "invenção circunstancial" (BORGES, 1997). O interesse está voltado em criar uma tensão entre ficção e história, ficção e filosofia, ficção e arte, ficção e educação, ficção e ensino, ficção e conhecimento. Trata-se de reescrever e reinterpretar, de compor uma escritura, criando novos movimentos que se entretecem onde as informações trazidas são verificáveis.

Para tanto é preciso se despir da representação costumeira, para que o ensino, no fluxo de um movimento de pesquisa e escrita, flua sem ares de uma história ilustrada. Deixar-se guiar pela vida e pela obra de uma criatura do pensamento, investigando como ocorre o seu pensar e, a partir desse procedimento, operar com pequenas inserções e cortes na busca pelos pormenores de uma vida e suas criações. E isto requer esforço, luta disciplinada do pensar, colocando em ação as potências de conhecer, de inventar, de pensar com renovação e achar modos de incorporar ideias para, quem sabe, ir um pouco mais longe do o que nos impõe o senso-comum, que apenas reproduz conhecimentos. Busca-se reconhecer a força do conhecimento empírico voltado a ser criação pela potência sinérgica do pensamento. Ultrapassar a lógica totalizadora, redutora e racionalizadora do conceito colocando-o para funcionar, também, como força empírica; um gesto sempre inacabado como é a vida.

Espírito consciente de si, em self-variance constante, que tem ciência que nada há neste processo de permanente, mas movimentos extratores de forças que favorecem como diz Corazza: "as culturas do dissenso" para reinventar 
novas formas, novas "significações de indivíduos e de grupos" (CORAZZA, 2011). Através de uma educação que promove uma pesquisa gaia, que aumente nossa potência de agir, longe da tristeza geradora de desesperança e do medo presente na contemporaneidade. Treinando o espírito para planejar a navegação com Paul Valéry, em águas plurais onde o conhecimento como invenção abre possibilidades criadoras no ensino de uma educação contemporânea. Navegação que não pode ser estabelecida previamente, senão no próprio navegar. Educação que opera com muitos códigos, pois é aí que está sua contemporaneidade, na inerente multiplicidade de possibilidades que o campo carrega ao admitir que o seu meio é de constantes mudanças e seu status é sempre provisório e variável. É disso que se trata!

\section{Como fazer?}

O trabalho da docência é um trabalho de pesquisa e o trabalho de pesquisa, quando se é professor, é também um trabalho de docência. O fazer dessa pesquisa não pode ser confundido com a apresentação ou constatação de uma verdade. A Educação é um lugar que se inventa no movimento da escrita pela leitura e da leitura pela escrita; nas relações que esse movimento comporta e, principalmente, na invenção e reinvenção do espaço-auleiro como um espaço de ficção.

Entende-se que é preciso dramatizar o conceito de verdade (DELEUZE, 1994); atentar para quais forças e que vontades este conceito qualifica e pressupõe por direito. Pois, sabe-se que qualquer produção de verdade sempre teve um pacto com a ficção. Disso resulta dizer que o que se quer com o trabalho da docência não é o de uma produção de verdade, mas a instauração de um multiverso de possíveis para o ensino.

Nesse sentido o fazer da Educação, assim como o da filosofia, para que continue possível precisa começar a compreender que o conhecimento, como um modo de incorporação da verdade é, sem dúvida, impossível. $\mathrm{O}$ conhecimento da possibilidade é o que se afirma como paixão (pathos). E a paixão é aquele movimento que "me faz sair de mim mesmo, empurra-me para fora de mim, para as coisas: é 'a maneira extrema de ver algo fora de si'" (PONTON, 2009, p. 53).

O que conta é um fazer educacional ao modo de um traçado que opera mais para uma geografia do que para uma história. É escrevendo que se escreve e se vira escrevedor, nos diz Raymond Queneau (1995), entende-se, então, que a educação, constituída pelos traçados de uma aula e pela prático de ensino, opera desse mesmo modo. Ou seja, atenta à ideia de que toda expressão só se expressa ao se expressar, já que inexiste como forma pré-definida ao expressado, procura que seu processo atue pelas e nas multiplicidades potenciais da expressão, sem a procura de uma estabilidade doada por um sentido unívoco ou pré-estabelecido. O objetivo está em dar mais atenção ao processo do que ao resultado em si. A aula é todo o processo e acontecimento e não meio para chegar a outro lugar que não o de sua própria vivência. 
Nesse sentido, a aula como um espaço de ficção, ao operar com atenção ao processo, se planeja para que, de algum modo, funcione. Esse planejamento precisa ser constituído via certo distanciamento. Trata-se de um distanciamento que visa tramar a dramatização desse espaço. Como esse espaço, o de uma aula, assume-se de antemão como um espaço da ficção, ele não opera por repetição com vias a representar ou imitar, analogamente, uma ideia. Decalcando-a como na concepção platônica de imitação. Pois, sua imitação (se é que ela ocorre) é fabricadora do processo pelo qual se constituiu uma ideia e não do objeto da mesma. Por isso o distanciamento se faz necessário. Uma vez que é via esse distanciamento, mesmo que especulativo, que se pode vislumbrar o vivível e o vivido por meio de sua reinvenção. Trata-se de uma operação tradutora.

Deste modo, ao repetir o processo de uma ideia o que ocorre não é repetição de fato, mas composição. Renova-se aquilo que a operação tradutora passou ao traduzir dos elementos filosóficos, científicos, artísticos operados em aula.

Tomemos a produção de Paul Valéry, que fez do processo a marca de sua escrita, como um modo de fabricar uma aula e, assim, procurar reinventar a educação por meio de si mesma. A produção valéryana está mais que entremeada por rasuras, artifícios da forma, mas quer constituir-se na e pela rasura. Adota a rasura como um estatuto paradoxal para a própria escrita. Uma escrita em que seus procedimentos, operações, mecanismos, voltam-se à composição de textos com fins a expressá-los para produzir o máximo de efeito ao leitor-ouvinte, leitor que se ouve e hesita a significar o lido entre som e sentido. Por isso a escrita valéryana está composta por uma variedade temática diletante e é aí que apoia sua consistência, em uma espécie de simultaneidade na qual sensível e inteligível atuam em reciprocidade. Operando, evidentemente, por uma relação indissociável entre teoria e prática, leitura e escrita.

Em domínios de interação mútua, no qual a escrita e sua outra metade, a leitura, agem como rasura, acaba por determinar o apagamento do que foi feito-lido-escrito. O que fica é uma mancha de sentido, uma tentativa de deliberar toda uma orbita por meio de qualidades próprias. Como pudesse se negar ao afirmar-se, atuar por meio de cortes e desvios, evasões, reescritas, repetições, atualizações, por fim, incompletudes.

Tem-se que Valéry, lido assim para servir como ferramenta para a Educação, não é um modelo, mas um modo de constituir forças fabricadoras de composições. Um movimento que não se interessa por uma história da verdade, como já dissemos antes, mas por uma história que nada narra, senão, a sua potência como contingência compositiva. Um escrever como experimento do trabalho de alguém que escreve para conhecer, e não para dar a ver o que já conhece. E, mesmo assim, o conhecido - de uma escrita e de uma aula -, se dá por uma relação constante com o incognoscível e imperceptível de cada aula-escrita, dá-se em um processo inacabado e sempre por recomeçar.

Agindo valéryanamente, ou seja, pensando que o pensamento age como um movimento em segredo que produz efeitos cria-se um distanciamento para ficcionalizar os modos de conceber uma aula. Algo como "[...] adivinhar por quais sobressaltos de pensamento, por quais bizarras introduções dos acontecimentos humanos e das sensações 
contínuas, depois de quais imensos minutos de languidez são reveladas aos homens as sombras de suas obras futuras, os fantasmas que as precedem" (VALÉRY, 1998, p. 19-21). Tais fantasmas, como movimentos em segredo, são os fantasmas das criações e anotá-los e, com isso fazer com que se constitua de palavras a sua matéria é como se insinuar ao modo de promover um método no qual, por intermédio de uma ação imitativa e tradutora do ato descrito, um novo ato promova adaptações possíveis do primeiro, tornando-se outro por meio da necessidade de seu uso e, a cada vez, promovendo uma nova necessidade.

Trata-se de conceber uma aula que visa operar por uma estratégia do desvio como força de constituição criadora. Ao modo do Pierre Menard, el autor del Quijote de Borges (1995), opera pela técnica do anacronismo deliberado e das atribuições errôneas. Visa, ao extrair conceitos, fazê-los servir a fins de uma potência ficcional e, por isso, produtora de sentidos que diferem. Doando a estes que os extraem, professores, alunos agentes de uma aula, a possibilidade potencial da invenção como modo de portar uma paixão pelo conhecimento.

No melhor dos casos - esse modo de tentar operar na educação via uma aula que se admita, a cada vez, como reinvenção de si -, cria possibilidades inesperadas que coloquem em jogo o próprio fazer, descentralizando uma prevista e imaginável autoridade do docente pesquisador.

Por que todo fazer pressupõe um campo empírico e experimental o exercício da apropriação de um pensar - que tenha o conhecimento como um campo de múltiplas variações onde o movimento de invenção visa superar a trivialização de suas próprias propostas - se torna possível na medida em que encontra espaço, não só para sua formulação como, também, evidentemente, para sua atuação.

No âmbito de nossas pesquisas esse espaço se tornou possível, também, através de oficinas promovidas pelo projeto Escrileituras: um modo de ler-escrever em meio à vida do programa Observatório da Educação CAPES/ INEP. Dentre as várias ações do projeto, foram oferecidas oficinas por meio de uma atividade de extensão denominada "Transcriações no cotidiano", que ocorreu entre 07 de junho e 25 de agosto de 2011, na Faculdade de Educação da Universidade Federal do Rio Grande do Sul. Fruto desse canteiro de experimentações, estas operações informes têm suas pesquisas cultivadas dentro do projeto Escrileituras. Terreno fértil e aberto ao esforço da criação, à variação espiritual, onde o serpensamento transforma-se e arrisca um novo olhar diante do espetáculo do mundo; para assim dizer-se, autoeducar-se, explorando as potências da linguagem no ensino e na pesquisa em Educação.

\section{Considerações finais}

É certo que este texto se apresenta, pelo menos para nós, como abertura e continuidade de pesquisa. Roland Barthes afirma a escritura como destruição de toda origem. Quando começa a escritura começa, também, a morte 
do autor (BARTHES, 1988). Valemo-nos de sua fala para afirmar que a Educação Contemporânea, parece-nos, carece da escritura para livrar-se de seu próprio ranço constitutivo, isto é, livrar-se de uma postura autoral com relação aos modos de conhecer e apostar em suas práticas como fluxo inventivo, como força produtora do novo e por isso, produtora de conhecimento. Caso contrário ela se volta para a defesa de uma identidade que representaria suas intenções. Não há intenções na Educação, não para uma Educação que deseja se afirmar como singularidade e potência criadora. O importante está em seu processo, como ela arma as composições e arbitrariedades dos encontros.

Nesse sentido o texto procurar mostrar: 1) que a autovariação, como afirmada por Paul Valéry, é constitutiva do conhecimento e da singularização do espírito e que, nesse sentido, a Educação tem de aprender a lidar com essa instabilidade em suas práticas; 2) que o conhecimento é um movimento inventivo do espírito e sua construção se vale da linguagem como potência ficcional e ferramenta ativa na construção de conhecimento; 3) que para lidar com a instabilidade e variação do pensamento pode-se criar um método, o Método do Informe, que visa associar "a vivência dos limites formais e a criação artistadora" (CORAZZA, 2014); e, finalmente 4) que todo pensamento conforma um fazer e este se prefigura em uma prática experimental desde que o espaço para a mesma seja, de algum modo, propiciado.

Em tudo isso "o mais difícil é ver o que existe” (VALÉRY, 1997, p. 103).

\section{Referências}

ADÓ, Máximo Daniel Lamela. Ensino de Sociologia na contemporaneidade. In: IX ANPED SUL, GT Sociologia da Educação, 2012. Caxias do Sul: 29 de julho a 01 de agosto de 2012, Universidade de Caxias do Sul, RS. <http://www.ucs.br/etc/conferencias/index.php/ anpedsul/9anpedsul/paper/viewFile/255/703>.

ADÓ, Máximo Daniel L. Prefácio. In: CORAZZA, Sandra. Caderno de Notas 1: projeto, notas \& ressonâncias. Cuiabá: EdUFMT, 2011. p. 09-12.

BARTHES, Roland. Rumor da língua. Tradução Mario Laranjeira. São Paulo: Brasiliense, 1988.

BORGES, Jorge Luis. Apresentação. In: SCHWOB, Marcel. Vidas imaginárias. Tradução Duda Machado. São Paulo: Ed. $34,1997$. p. 9-10.

BORGES, Jorge Luis. Ficciones. Barcelona: Emecé, 1995.

CAMPOS, Augusto. Paul Valéry: A serpente e o pensar. São Paulo: Brasiliense, 1984.

CORAZZA, Sandra Mara. Método Valéry-Deleuze: um drama na comédia intelectual da educação. Educação \& Realidade, Porto Alegre, v. 37, n. 3, dez. 2012. Disponível em: <http:/www.scielo.br/scielo.php?script=sci_arttext\&pid=S2175-62362012000300016\&ln $\mathrm{g}=\mathrm{en} \& \mathrm{nrm}=\mathrm{iso}>$. Acessado em: 13 jun. 2014.

Educação Por Escrito, Porto Alegre, v. 6, n. 1, p. 81-97, jan.-jun. 2015 
CORAZZA, Sandra Mara. O que se transcria em educação? Porto Alegre: UFRGS; Doisa, 2013.

CORAZZA, Sandra. Caderno de Notas 1: projeto, notas \& ressonâncias. Cuiabá: EdUFMT, 2011.

DELEUZE, Gilles. Nietzsche. Tradução Alberto Campos. Lisboa: Ed. 70, 1994.

DESCARTES, René. Discurso do Método. Para bem conduzir a própria razão e procurar a verdade nas ciências. Tradução Maria de Lourdes Teixeira. São Paulo: Martins Editora, 1955.

HEIDEGGER, Martin. Nietzsche. Tradução Juan Luis Vermal. Barcelona: Ed. Destino, 2000. Segundo tomo.

LÖWITH, Karl. Paul Valéry. Rasgos centrales de su pensamiento filosófico. Traducão Griselda Mársico. Madrid: Katz Editores, 2009.

PIMENTEL, Brutus Abel Fratuce. Paul Valéry: estudos filosóficos. 2008. Tese (Doutorado em Filosofia) - Faculdade de Filosofia, Letras e Ciências Humanas, Universidade de São Paulo, São Paulo, 2008. Disponível em: <http://www.teses.usp.br/teses/disponiveis/8/8133/ tde-19012009-162232/>. Acesso em: 23 set. 2012.

PONTON, Olivier. Nietzsche. Fazer do conhecimento o mais potente dos afetos. In: MARTINS, André. O mais potente dos afetos: Spinoza e Nietzsche. São Paulo: Martins Fontes, 2009, p. 36-58.

QUENEAU, Raymond. Exercícios de estilo. Tradução Luiz Rezende. Rio de Janeiro: Imago, 1995.

SCHWOB, Marcel. Vidas imaginárias. Tradução Duda Machado. São Paulo: Ed. 34, 1997.

VALÉRY, Paul. Variedades. Tradução Maiza Martins de Siqueira. São Paulo Iluminuras, 2011.

VALÉRY, Paul. Introdução ao método de Leonardo da Vinci. Tradução Geraldo Gérson de Souza. São Paulo: Ed. $34,1998$.

VALÉRY, Paul. Monsieur Teste. Tradução Cristina Murachco. São Paulo: Ática, 1997.

VALÉRY, Paul. A alma e a dança e outros diálogos. Tradução Marcelo Coelho. Rio de Janeiro: Imago, 1996.

VALÉRY, Paul. Variedades. Tradução João Alexandre Barbosa. São Paulo: Iluminuras, 1991.

VALÉRY, Paul. O pensamento vivo de Descartes. Tradução Maria de Lourdes Teixeira. São Paulo: Martins Editora, 1955.

VALÉRY, Paul. Mauvaises Pensées \& autres. Paris: Gallimard, 1947.

VALÉRY, Paul. Tel Quel I. Paris: Gallimard, 1941.

Endereço para correspondência:

Máximo Daniel Lamela Adó

Rua Vinte e Quatro de Outubro, 1348/204

90510-001 Porto Alegre, RS, Brasil

<maximo.lamela@ufrgs.br>

Recebido em: junho/2014

Aceito em: dezembro/2014 